\title{
Stress CMR as a gatekeeper to complete revascularisation in STEMI patients with moderate-severe bystander disease at primary percutaneous coronary intervention
}

\author{
Amardeep Ghosh Dastidar*, Alexander Carpenter, Elisa McAlindon, Tom Johnson, Julian Strange,
} Angus K Nightingale, Andreas Baumbach, Chiara Bucciarelli-Ducci

From 18th Annual SCMR Scientific Sessions

Nice, France. 4-7 February 2015

\section{Background}

Nearly $40 \%$ of the patients presenting with ST Elevation Myocardial Infarction (STEMI) have multivessel disease (MVD). Currently ESC and the ACC/AHA guidelines recommend revascularization of the culprit artery only. 2 recent trials (PRAMI and CVLPRIT) have shown a superiority of complete in-hospital revascularisation as compared to culprit only treatment. Although the mortality in the 2 groups in the trials were not significantly different but the composite end point was, which was mainly driven by ischaemia.

\section{Aim}

To assess the role of stress CMR as a gatekeeper to complete revascularisation in STEMI patients with moderate to severe bystander disease, treated with Primary PCI (PPCI) of the culprit lesion.

\section{Methods}

The study was performed from the data collected on consecutive patients who underwent PPCI between September 2011 - September 2013 at a tertiary centre in the South-West of England. A non-culprit lesion was considered to be moderate to severe if the stenosis was $50-75 \%$ in large proximal epicardial vessel or $70-90 \%$ elsewhere. Severe or critical bystander disease was excluded as the best treatment for those was deemed to be direct revascularisation without Fractional Flow reserve (FFR) assessment. The diagnostic accuracy of

\footnotetext{
NIHR Cardiovascular Biomedical Research Unit, Bristol Heart Institute, Bristol,
} UK

\section{Results} patients (33\%). 157/391 (40\%) underwent stress CMR guided approach. The remaining 234 patients either underwent direct revascularisation (presence of severe or critical stenosis) or underwent a stress echo guided treatment or died in hospital or were lost to follow up. Of those patients undergoing stress CMR, only $39 \%$ (61/157) had evidence of inducible myocardial perfusion defect. Putting these figures in a FFR guided approach model our study showed an average saving of $£ 302$ per patient or $\$ 1558$ per patient in a UK based or US based cost assessment, respectively.

\section{Conclusions}

Our study demonstrated that, less than $40 \%$ patients undergoing PPCI with moderate to severe by-stander non-culprit coronary artery disease need further revascularisation. As a gatekeeper to complete revascularisation, stress CMR was also found to be a cheaper management strategy in a cost analysis model when UK or US-based costs were assumed. 
Table 1 Cost tariff

\begin{tabular}{ccc}
\hline & United Kingdom & United States \\
\hline Stress CMR (Cost per correct diagnosis) & $£ 548(£ 623)$ & $\$ 621(\$ 706)$ \\
\hline Coronary angiography & $£ 1052$ & $\$ 2989$ \\
\hline CA + FFR & $£ 1512$ & $\$ 3704$ \\
\hline PCl & $£ 3676$ & $\$ 6529$ \\
\hline Cost of PCl (follow on from FFR) & $£ 2164$ & $\$ 2825$ \\
\hline
\end{tabular}

\section{Funding}

This study was funded by the National Institute for Health Research Biomedical Research Unit in Cardiovascular Disease at the University Hospitals Bristol NHS Foundation Trust and the University of Bristol.

- Convenient online submission

- Thorough peer review

- No space constraints or color figure charges

- Immediate publication on acceptance

- Inclusion in PubMed, CAS, Scopus and Google Scholar

- Research which is freely available for redistribution 